General Rykatcheff, director of the Russian Meteorological Service, the Committee recommended that meteorological institutions should take part in observations of earthquake phenomena. With regard to Antarctic exploration, the Committee expressed the opinion that it is highly desirable (I) that the resuits of these explorations should be completed by data from the observatories already existing in the southern hemisphere, and by those made on board vessels traversing the southern oceans; (2) that new meteorological stations should be established in the southern part of the Antarctic regions, and especially that magnetic observations should be organised; (3) that magnetic determinations over the whole globe should be made simultaneously with those made during the expeditions. With reference to the valuable researches of Dr. Hildebrandsson relating to the great centres of action of the atmosphere (which have already been noticed in our columns), the following resolution was adopted:- "The Committee appreciates the high interest attached to observations made in a regular manner in different regions which seem to possess special importance as to our knowledge of the general laws of the motions of the atmosphere." Profs. v. Bezold and Mascart drew attention to the proposed establishment of a very complete meteorological and magnetical observatory at the Azores by the Prince of Monaco, assisted by Captain Chaves, of the Portuguese navy, who has entirely devoted himself to the realisation of this undertaking. On the question of the calculation of daily meteorological means, it was decided that if the exact formula

$$
\frac{0+24}{2}+1 \ldots+23: 24
$$

is not adopted the midnight observation should be taken into account at the end of the day, as is already done at most stations, according to the formula

$$
1+2+3 \ldots+24: 24 \text {. }
$$

On the proposal of Dr. Hann to publish tables of diurnal range of temperature for each country in a special form, the Committee, while appreciating the interest and importance of the proposal, expressed its opinion that, as the question possessed a general bearing, it should be examined by a sub-committee, which should determine the form of table to be adopted by all countries. On the subject of the importance of actinometric observations, also brought forward by Dr. Hann, the Committee expressed the hope that the sub-committee for terrestrial and solar radiation would present a report upon that subject at the next International Congress. M. Violle submitted a note on the various methods employed for actinometric measurements. On the proposal of Dr. Pernter as to the desirability of the restriction of observations with the wet-bulb thermometer and the multiplication of observations with the hair hygrometer, the Committee came to no decision, pending the presentation of a full report upon the question. Dr. Paulsen, director of the Danish Meteorological Institute, drew attention to the importance for weather prediction of the laying of a cable between Iceland and Europe, towards which the Danish Government and the Great Northern Telegraph Company were prepared to make a considerable annual subvention. The Committee fully recognised the importance of the proposal, and expressed its hope of the ultimate success of the project. Profs. Neumayer and $v$. Bezold made a proposal relative to the publication of an international periodical weather report (recently referred to in our columns), which should contain ten-day means from about a hundred stations. The Committee was of opinion that it would be desirable that a definite plan of the proposed publication should be prepared for examination by each meteorological service. A subcommittee, composed of MM. Pernter (president), Billwiller, Neumayer, Rykatcheff, Mohn and Tacchini, was nominated for the purpose of considering the extension and improvement of international telegraphy for weather prediction. Finally, it was decided that the International Meteorological Committee and the various sub-committees should meet in Paris in the year 1900 , immediately after the Meteorological Congress which will take place on the occasion of the Exhibition. This Congress will probably be held during the first half of September. We are indebted to M. Lancaster's summary in Ciel et Terre for the notice of this meeting.

\section{THE COMING SHOWER OF LEONIDS.}

DURING the past few years English observers, in their efforts to witness returns of the Leonid meteors, have met with little but disappointment. Either the firmament has been overcast at the important time, or the display has been very weak. The rarity and singular attractiveness of a really fine mieteoritic exhibition are such that the immediate prospect of viewing an event of the kind has aroused great interest in the whole subject of shooting stars. But we have been a little premature in our anticipations in recent years, and looking for the appearance of the meteors before the vanguard of the denser portion of the stream had begun to cross the earth's path. There can, however, be no doubt as to the character of the ensuing display. The earth will be sure to encounter one of the richest regions of the orbit at the middle of November, but whether or not this collision will occur at an hour perfectly suitable for its observation remains to be seen. It must be admitted that the exact time of the rencontre cannot be definitely stated. The materials upon which computations have to be based are not sufficiently numerous and consistent to enable exact deductions to be drawn from them. Moreover, there is evidence to show that the system of meteors is constantly undergoing changes. The particles are spread out, and are still spreading out, over a very considerable section of the orbit, and are subject to perturbations by the larger planets. Different sections of the stream are affected unequally, so that the whole system, both as regards its conformation and distribution, suffers from such irregular disturbances, that we must be prepared for the visible signs of developments of an unexpected character. In the present state of our knowledge it is impossible for us to allow for all the various circumstances and conditions which control the visible aspect of the shower, from year to year, and modify its orbital elements.

Calculations which have been made independently by several authorities show that the influence of Jupiter and Saturn, since the last return of the shower in 1866 , has been exerted in increasing the node, so that the phenomenon may be expected a day late in the present year It will probably occur just before sunrise on November I6. Drs. Stoney and Downing, in a paper published in the Proceedings of the Royal Society, vol. lxiv. p. 406, state that a noteworthy outcome of their investigations is that the meteor-group which gave rise to the display in 1866 , made a near approach to Saturn in 1870 , and to Jupiter in 1898 . On the latter occasion the meteor-cloud was distant from Jupiter by an interval of space less than that separating the earth and the sun. Berberich (Ast. Nach., $\left.35^{26}\right)$ has also discussed the orbit-perturbations of the Leonid stream, and concludes that the meteors will appear about a day later than they would have done under normal conditions. If there had been the average annual displacement of the node (equal IO2"6) the recurrence of the shower might have been anticipated on November 15 at about I a.m., but the perturbations seem to have increased the longitude of the node to the extent of $\mathrm{I}^{\circ}$; so that the greatest intensity of the display must be awaited on the morning of November 16 , in the twilight preceding sunrise.

No. I 564 , voL. 60$\rceil$ 
But it must be admitted that these deductions are liable to some uncertainty. Last year the predicted latecoming of the meteors was far from being corroborated by observation. The maximum number of meteors was recorded on the morning of November i 5 , and very few Leonids were presented on the following morning, though computation had indicated the latter as the time of maximum. In view of the prevailing doubts there seems no alternative but to watch for the shower throughout the morning of the 15 th, and failing its brilliant apparition then, to repeat the watch on the morning of the 16th. The maximum may be displayed at any time between November 15, oh. 3om. a.m. and November 16, 6h. 3om. a.m.

In England a November sky is cloudy on at least three nights out of four, and this year we shall have moonlight to consider as well, for cur satellite will be nearly full, and must largely detract from the striking character of the display. Should the meteors appear on the morning of the 15 th, they might, however, be seen on a dark sky, for the moon will set about $2 \frac{1}{2}$ hours before sunrise. The Leonids are fine meteors; a large proportion of them are as bright as ist mag. stars, and, notwithstanding moonlight, will create a conspicuous effect if they return in great numbers. On the occasion of the last grand display on the morning of November I4, I866, the writer was much struck with the number of tolerably bright meteors, and observed several which were many times brighter than Venus at her best. These Leonid fireballs gave lightning-like flashes, and left short green streaks, enduring for five, ten, fifteen minutes, and even more. The approaching display will be sure to supply a few of these splendid objects.

At every station where the weather enables the shower to be successfully witnessed, certain features ought to be particularly recorded. The nieteors should be counted, and the time of maximum ascertained. It will be useful also to determine the hourly rate of apparition by noting at certain regular intervals the number which appear. By counting during short intervals and continuing the work for several hours, the rise and fall of the display as well as the number per minute at and near the time of maximum might possibly be obtained. In the event of an exceedingly abundant display, similar to that seen in America in I833, the observer may feel bewildered and find it impossible to record the exact numbers. In such a case the figures should be estimated as carefully as possible.

Another feature will be to preserve a description of the time, brightness and apparent paths of any specially fine Leonids that may be visible. The paths should be marked on a celestial globe or suitable star-map, and the Right Ascension and Declination of their beginning and end points registered in a book properly ruled for the purpose. The length, duration and possible drifting of the luminous streak, left by every bright meteor, should also receive attention. Near the time of maximum, however, these details may be disregarded, as it will be necessary for the observer to concentrate his efforts to fixing the time of the maximum and strength of the display. A table with writing material and a lamp should be at hand so that numbers and notes can be hurriedly recorded by the observer almost without diverting his attention from the heavens. With more than one observer the various aspects of a meteoric shower can be fully recorded, but it is impossible to suppose that one person can watch its progress and record all the details presented.

Observers need not specially record the meteors with the main object of fixing the centre of radiation. We have already obtained a great number of eye-estimates of this position, and these must be put aside for the more accurate values obtainable by photography. No doubt the latter method will be extensively brought into requisition, though the bright moonlight will afford
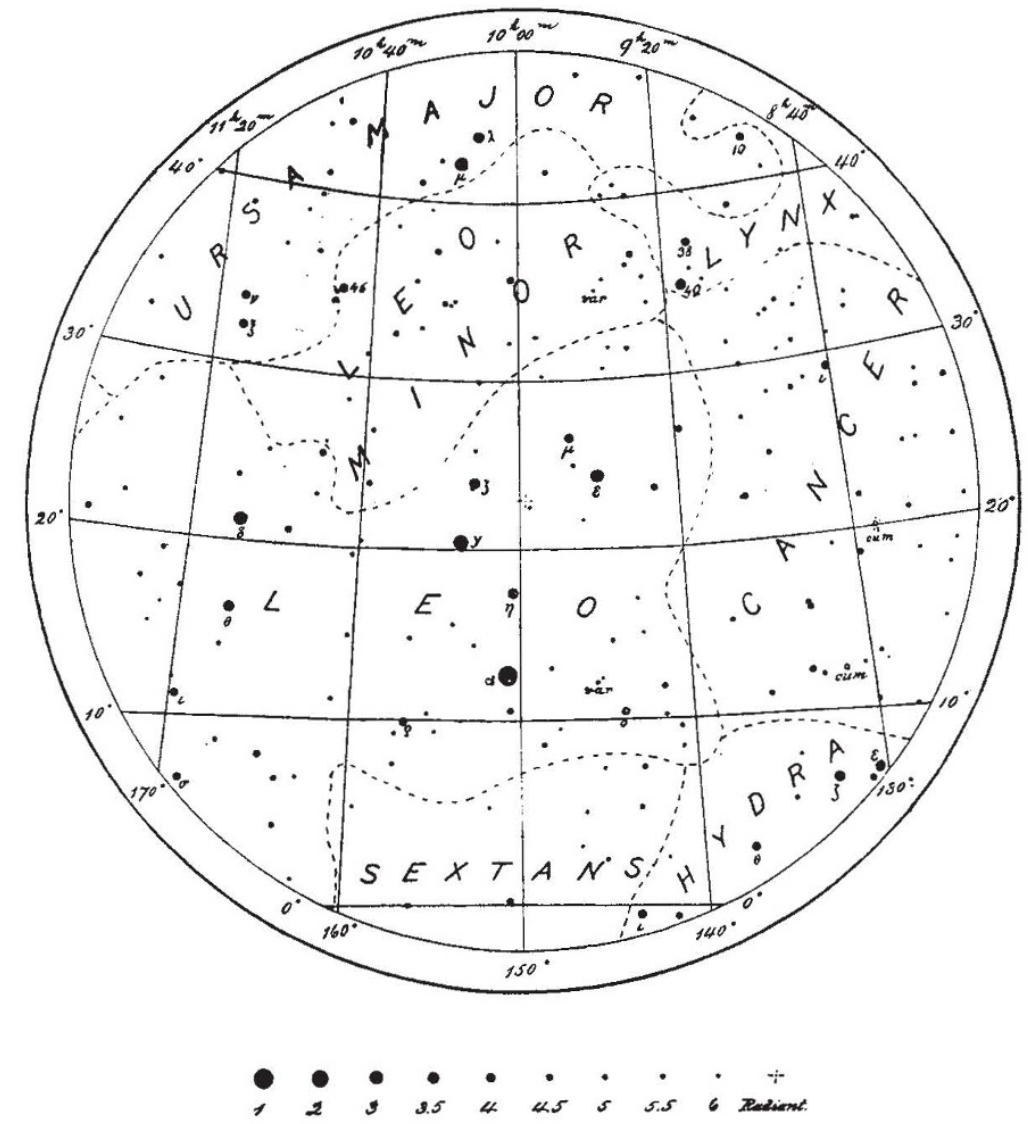

a serious hindrance on the present occasion. The Leonids begin to fall as early as November 7, and the shower is sustained over a fortnight. It will be very important to look for the meteors of this stream between about Novenuber 7-II, and record the paths of those visible with a view to definitely ascertaining the position of the radiant. At this early period of the shower's activity it is not probable that the photographic method will be appealed to. It is to be hoped that all regular meteoric observers will follow the progress of the shower with close attention during the second week of November in this year, for the questions as to the date of commencement of the shower and as to whether the radiant is a shifting or stationary one are very interesting features requiring settlement.

W. F. DENNING. 